\title{
HINGED PERFORATED DIAPHRAGMS FOR THE TRIAL FRAME
}

BY

\author{
Percival J. Hay
}

SHEFFIELD

Opaque disks with a central perforation are in common use for reducing the dilated pupil artificially to the normal size when testing a patient's vision under a mydriatic. The advantages attached to these disks are well known. They reduce spherical and chromatic aberration and sharpen up the image by preventing glare. In practice they are often difficult to use, in that with some trial frames they hide the axis markings when placed in the front

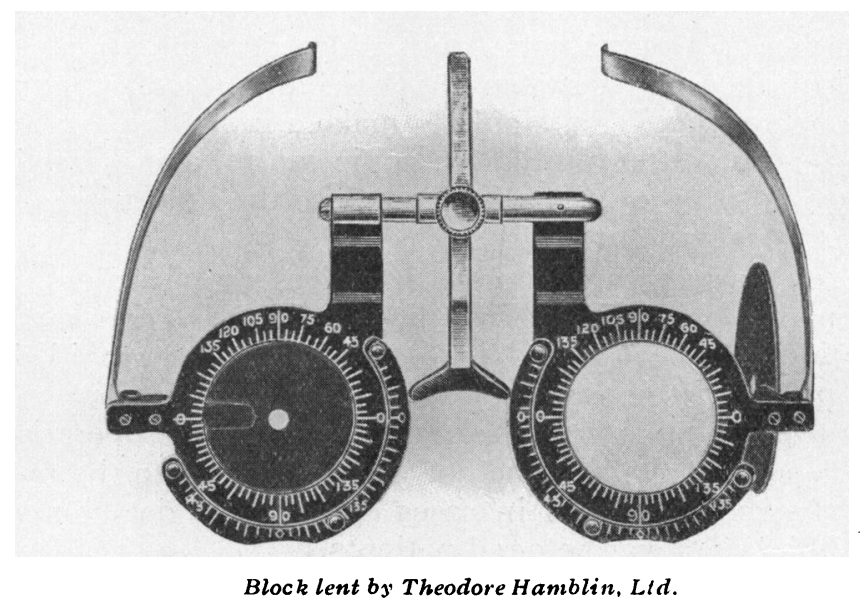

cells, and if inserted in the back cell they often do not allow a lens of even medium power to be inserted in the same cell.

Messrs. Theodore Hamblin have made for me perforated diaphragms which are hinged to the back of the trial frame, where they not only give the advantages already mentioned, but prevent reflections of the retinoscopy lamp from the back surface of the trial lens, and further make it easy to drop the lenses into the back cell without danger of their dropping to the floor. I have used the device for some time and find it extremely useful. It is necessary, of course, to determine the P. D. for each eye beforehand. 